\title{
Advancing the Field of Health Literacy
}

\author{
Sunil Kripalani, MD, MSc, ${ }^{1}$ Michael K. Paasche-Orlow, MD, MA, MPH, ${ }^{2}$ \\ Ruth M. Parker, MD, FACP', Somnath Saha, MD, MPH ${ }^{3,4}$ \\ 'Emory University School of Medicine, Atlanta, GA, USA; ${ }^{2}$ Boston University School of Medicine, Boston, MA, USA; \\ ${ }^{3}$ Portland Veterans Affairs Medical Center, Portland, OR, USA; ${ }^{4}$ Oregon Health \& Science University, Portland, OR, USA.
}

DOI: $10.1111 / \mathrm{j} .1525-1497.2006 .00568 . \mathrm{x}$

J GEN INTERN MED 2006; 21:804-805.

I n 1992, the National Adult Literacy Survey (NALS) showed that $40 \%$ to $45 \%$ of adult Americans struggled with functional literacy tasks. ${ }^{1}$ In early 2006, the results of the National Adult Assessment of Literacy indicated that the status of literacy in the United States remains much the same. ${ }^{2}$ Over 90 million adults lack the literacy skills needed to effectively function in the present health care environment. ${ }^{3}$

Low health literacy is associated with less medical knowledge, infrequent receipt of preventive services, increased hospitalization and use of emergency care, and worse control of chronic diseases. ${ }^{4}$ In 2004, the Institute of Medicine (IOM) called for additional research into the associations and consequences of low health literacy. Among the items highlighted by the IOM committee were the need to develop new measures of health literacy, approaches to improve health communication in diverse populations, interventions to reduce the negative health effects of low literacy, and ways to address health literacy in graduate medical education and the health system. ${ }^{3}$

This special issue of JGIM responds to the priority areas outlined in the IOM report by bringing together state-of-the-art research related to the role of literacy in health care. The research articles and commentaries in this issue will provide insight for clinicians, educators, researchers, administrators, and policy makers on addressing literacy in various health care settings.

Among the many excellent original manuscripts featured in this special issue are several important health outcome studies. Sudore and colleagues lead off the issue with their longitudinal analysis of the Health, Aging, and Body Composition Study, demonstrating for the first time that low health literacy is an independent risk factor for mortality. In a 2-year study of patients with asthma, Mancuso and Rincon show that literacy is associated with asthma outcomes and that this relationship appears to be mediated by other variables, particularly asthma knowledge. More work like this is needed, to clarify not only the extent to which literacy is associated with disease control, but also to provide a better understanding of the potential mechanisms behind such relationships.

In another longitudinal study, Lincoln and colleagues describe the association between literacy and the severity of depression among adults with alcohol and drug dependence.

Address correspondence and requests for reprints to Dr. Kripalani: Division of General Medicine, Emory University School of Medicine, 49 Jesse Hill Jr Dr SE, Atlanta, GA 30303 (e-mail: skripal@emory.edu).
A particularly innovative report in this issue is a clinical trial by Weiss and colleagues, who randomized patients with depression and low literacy to receive adult literacy education as an adjunctive therapy. The groundbreaking findings of this study should serve as a call for greater collaboration between the medical and adult education communities.

Given the importance of literacy in chronic disease management, it is surprising how few previously published articles had investigated the relationship between literacy and medication use. Four research papers in this issue shed some light on this area. Studies by Kripalani, Fang, and Davis indicate that literacy is associated with patients' ability to correctly identify their medicines, understand medication dosing instructions, and understand prescription bottle warning labels, respectively. However, the relationship of literacy with medication adherence and clinical parameters is less clear. Fang found no association between literacy and adherence to warfarin therapy or anticoagulation levels. By contrast, Paasche-Orlow actually found better adherence and viral load suppression among patients with low literacy and HIV, contradicting findings of prior studies. ${ }^{5,6}$ It is evident that more research is needed to clarify how literacy may impact various aspects of medication use and adherence.

Two articles address the important question of whether differences in literacy contribute to racial and socioeconomic disparities in health and health care. Using data from the NALS, Sentell found that differences in literacy helped explain disparities in disability and chronic illness by race and educational attainment. Using data from a large cohort study, Howard similarly found that different literacy levels contributed to disparities in health status but not in vaccination rates. These findings raise as many questions as they answer.

Other original research papers in this issue concern comprehension of informed consent, follow-up after an abnormal Pap smear, and the performance of health literacy screening questions. Baker offers a perspective on the meaning of health literacy and the challenges inherent in its measurement. Three commentaries have been included to highlight federal and other national activities, strategies for teaching about health literacy and clear communication, and guidance for health systems to adapt to the needs of low-literacy patients. Many other resources are catalogued online by the SGIM Health Literacy Interest Group. ${ }^{7}$

It has been a privilege, a pleasure, and a great learning experience to review the latest work in health literacy and compile this special issue of JGIM. We wish to thank all of 
the authors who submitted their manuscripts for consideration, as well as Pfizer Global Pharmaceuticals for funding the publication of this issue through an unrestricted grant. We are indebted to the staff of the journal as well as the wonderful members of the Expert Review Panel who performed many of the manuscript reviews, anchoring the peer review process. (See front matter for a complete listing.) Finally, we thank Vice Admiral Richard H. Carmona, MD, MPH, the current United States Surgeon General, for his support of this issue and for making health literacy an integral part of his public health agenda. We hope you all enjoy the issue and include efforts to improve health literacy in your own clinical practice, research, and educational activities.

Dr. Kripalani is supported by a K23 Mentored Patient-Oriented Research Career Development Award (K23 HL077597). Dr. Saha was supported by awards from the Department of Veterans Affairs Health Services Research \& Development Service Advanced Research Career Development Program and from the Robert Wood Johnson Foundation Generalist Physician Faculty Scholars Program.

\section{REFERENCES}

1. Kirsh I, Jungeblut A, Jenkins L, Kolstad A. Adult Literacy in America: A First Look at the Findings of the National Adult Literacy Survey. Washington, DC: National Center for Education Statistics, U.S. Department of Education; 1993.

2. Kutner M, Greenberg E, Baer J. National Assessment of Adult Literacy (NAAL). A first look at the literacy of America's adults in the 21 st century. Available at: http://nces.ed.gov/naal. Accessed May 2, 2006.

3. Institute of Medicine. Health Literacy. A Prescription to End Confusion. Washington, DC: National Academies Press; 2004.

4. DeWalt DA, Berkman ND, Sheridan S, Lohr KN, Pignone MP. Literacy and health outcomes: a systematic review of the literature. J Gen Intern Med. 2004;19:1129-39.

5. Golin CE, Liu H, Hays RD, et al. A prospective study of predictors of adherence to combination antiretroviral medication. J Gen Intern Med. 2002; 17:756-65.

6. Kalichman S, Ramachandran B, Catz S. Adherence to combination antiretroviral therapies in HIV patients of low health literacy. J Gen Intern Med. 1999;14:267-73.

7. Society of General Internal Medicine Health Literacy Interest Group. Available at: www.sgim.org 